\title{
Recent Development of Non-Thermal Cold Plasma Technology for Safe and Sustainable Seafood Processing: A Review
}

\author{
Pooja Saklani ${ }^{1}$, Siddhnath ${ }^{1}$, Sambit Kishor Das ${ }^{2}$, Sarita Kumari Das ${ }^{3}$, Subal \\ Kumar Ghosh ${ }^{2}$ and Shiv Mohan Singh ${ }^{4 *}$ \\ ${ }^{1}$ Department of Fish Processing Technology, Faculty of Fishery Sciences, \\ WBUAFS Kolkata, India \\ ${ }^{2}$ Department of Post Harvest Technology, Central Institute of Fisheries Education, \\ Mumbai, India \\ ${ }^{3}$ Department of Fisheries Resource Management, Faculty of Fishery Sciences, \\ WBUAFS Kolkata, India \\ ${ }^{4}$ College of Fishery Science, NDVSU, Jabalpur, India \\ *Corresponding author
}

\section{A B S T R A C T}

\section{Keywords}

Non-thermal, Cold

Plasma technology,

Seafood processing

Article Info

Accepted:

26 October 2019

Available Online:

10 November 2019
Seafood is one of the major protein sources in the world. Seafood products are praised worldwide for their high nutritional value and are increasingly popular among consumers. Consumer preferences range from fresh products, eaten raw or minimally processed seafood. So quality, safe and nutritionally rich processed seafood is high in demand. Cold Plasma (CP) is a novel non-thermal technology, potentially useful in the agriculture and food processing settings. Heat treatment can cause undesirable protein denaturation, non-enzymatic browning, loss of vitamins and volatile flavor compounds, freezing point depression, and flavor changes. $\mathrm{CP}$ has gained attention in recent years as a potential alternative method for chemical and thermal disinfection in foods using ambient or moderate temperatures and short treatment times in seafood sector. This review provides a critical summary of the studies to decontamination of seafood products using cold plasma technology along with a summary of the mechanisms involved. In addition, the review also discusses the effects of cold plasma on quality of seafood products, highlights some emerging applications of plasma technology in the seafood industry.

\section{Introduction}

Seafood is high in nutritional value, containing high-quality proteins, omega-3 fatty acids, essential micronutrients, minerals and vitamins (Murray and Burt, 2001). Globally, seafood consumption has grown exponentially over the past few decades. Abreast this increase in demand and consumption, food safety has become a vital public-health concern. Pathogens such as Listeria monocytogenes, Escherichia coli O157: H7, Campylobacter jejuni and Salmonella spp. can easily thrive on seafood, 
causing severe foodborne illness in consumers.

Traditional thermal-based food-processing methods such as appertization, pasteurization, and canning have been dependent on high temperature, to ensure prolonged shelf life and seafood safety. Heating has a lethal effect on both vegetative cells and spores of any microbes. Thermal treatment also results in concurrent consequences, such as a decrease in nutritional properties such as vitamins or denaturation of proteins, and sometimes the undesirable alteration in the fresh flavour in food (Birwal, 2019). Additionally, lipid oxidation is a significant cause of rancidity and off-flavours during subsequent storage. This is particularly the case for seafood that contains substantial amounts of polyunsaturated fatty acids.

As human evolution progressed, the way food is consumed, and their priorities have also been evolved. The consumption of processed foods is on the rise due to change in lifestyle, particularly in urban and semi-urban areas. Today's consumer is also extremely aware of the requirement of nutritionally superior shelfstable processed products whose sensory attributes are as close to the fresh product as possible. This has prompted food processing professionals to investigate novel and alternate technologies that have the potential to inactivate microorganisms in the seafood matrix with minimal change to preserve the seafood constituents. The novel approach has been to eliminate the use of heat treatment while targeting the set objective of improved safety and shelf life of the beverage leading to a category of non-thermal treatment technologies. Several such non-thermal high hydrostatic pressure (HPP), pulsed electric field (PEF), oscillating magnetic field, ionizing irradiation, ultrasound (US) pulsed light (PL), cold plasma (CP) and ozone (Zhao et al., 2019).These technologies retain nutritional and sensory properties quality of foods such as fruit and vegetables (Ramazzina et al., 2015; Gomez-Lopez et al., 2005), fish (Erkan et al., 2011; Rode and Hovda, 2016; Okpala, 2014), or fresh and ready-to-eat meat products (Ganan et al., 2013; McDonnell et al., 2014) by inactivating of spoilage and pathogenic microorganism better than conventional or traditional methods.

Plasma is a mixture of charged ions, radicals, electrons and neutrals in gaseous form. Cold plasma technology is emerging, green processes have evolved in recent times in food industries, and its application on seafood industries has been encouraging. In this paper, we have reviewed the important aspects of nonthermal processing for seafood.

\section{What is cold plasma?}

Cold plasma (CP) is an emerging non-thermal technology that could potentially decontaminate the surfaces of fresh produce. This antimicrobial intervention offers the advantage of being chemical and water-free, in addition to being able to operate openly and continuously at atmospheric pressure (Niemira, 2012).

Plasma is a quasi-neutral gas. Matter on earth exists mostly in three distinct phases (gas, liquid and solid) but when the universe is considered as the fourth state of matter which abundantly exists. So, Plasma is hence referred to as the fourth state of matter, next to solids, liquids and gases. It containing free electrons, ions and neutral particles and more than $99 \%$ of the visible matter in the universe are in the plasma state. It is a mixture of an electrified gas with chemically reactive compounds that consists of ions, free electron, activated and metastable species ( $\mathrm{NOx}-$ ), free radicals like reactive oxygen species (ROS), reactive nitrogen species (RNS) neutral particles (excited atoms and molecules), and 
quanta of electromagnetic photons (visible, UV-A, and UV-B) (Tendero et al., 2006; Mir et al., 2016; Ekezie et al., 2017; Misra et al., 2011; Afshari and Hosseini, 2012; Mir et al., 2016; Simoncicova et al., 2018). Use of electrical discharges and low temperature make this process practical, cost-effective and suitable for decontamination of various food products where heat treatment is not adequate (Afshari and Hosseini, 2012).

\section{Plasma Chemistry: History and Process}

Plasma was first discovered by Irving Langmuir (1881- 1957) in 1928. Plasma technology is based on a physical principle. Matter changes its state when power is supplied to it: solids become liquid, and liquids become gaseous. If even more power is provided to a gas, it is ionized and goes into the energy-rich plasma state, the final state of matter which exists over a vast range of temperature and pressure.

Plasma (at low-pressure or atmospheric pressure) produced by coupling energy to a gaseous medium by several means such as mechanical, thermal, chemical, radiation, nuclear, or by voltage application, or electromagnetic waves injection and also by a combination of these to dissociate the gaseous component molecules into a collection of ions, electrons, charge-neutral gas molecules, and other species (Mudgil and Mudgil, 2019)

Within nonthermal plasmas, plasma state can be attained by the application of energy in several forms including; thermal, electric or magnetic fields and radio or microwave frequencies, which increases the electrons kinetic energy resulting in increased number of collisions in the gas-forming plasma products like electrons, ions, radicals and radiation of varying wavelengths including that in the UV ranges (Thirumdas et al., 2017). In the generation of cold plasma, most of the coupled electrical energy is channelled to electron component instead of heating the entire gas stream, so the temperature of massive particle remains near the room temperature, these characteristics make it suitable to be used in processes in which high temperature is not desirable (Nehra et al., 2008). In contrast, conventional devices generated plasma do not ionize all of the atoms in a gas, even for hot (i.e., thermal) plasmas, such as welding arcs and spark plugs (Fridman et al., 2005). Within these hot plasmas, all species are incredibly reactive. Determining factor for the production of cold plasma by various types of reaction can be estimated by the chemical composition of gases used in it (Lieberman and Lichtenberg, 2005; Niemira and Gutsol, 2011).

\section{Types of Plasma}

Type of energy supplied and amount of energy transferred to plasma initiate a change into the temperature of the electron which leads to the classification of plasma into two groups hightemperature plasma and low-temperature plasma (Nehra et al., 2008). High-temperature plasma implies that neutral species of an electron, ions and neutral species are in a thermal equilibrium state. Low-temperature plasma can be further subdivided into thermal plasma (quasi-equilibrium plasma), also called local thermodynamic equilibrium (LTE) plasmas where species are in balance or near equality between electrons, ions and neutrals and nonthermal plasma(NTP) (nonequilibrium plasma), and also called non-local thermodynamic equilibrium plasmas (nonLTP) (Tendero et al., 2006).

Plasma can also be distinguished into two classes depending on the pressure conditions, as high-pressure and low-pressure plasma. Another type of plasma which is generated at normal atmospheric pressure, known as atmospheric pressure plasma. 
This type of plasma production is cost effective because it does not require reaction chambers to maintain pressure (Pankaj et al., 2018). The nonthermal plasma, where electrons and more massive species are in thermal non-equilibrium, is referred to as cold plasma $(\mathrm{CP})$. Cold atmospheric plasma $(\mathrm{CP})$ is a novel nonthermal process with great antimicrobial potential.

The antimicrobial efficacy of $\mathrm{CP}$ is beneficial to food retailers and producers for extending shelf-life and ensuring food safety of fresh commodities along the food chain (Smeu and Nicolau, 2014).

\section{Generation of cold plasma}

\section{Power Sources}

Power sources used for the generation of atmospheric pressure plasma are microwave, $\mathrm{RF}$ (radio frequency), pulsed, AC (alternating current), DC (direct current) or pulsed high voltages applied with repetition rates in the kilohertz range and mechanical, thermal, nuclear, electricity, radiation, extremely rapid compression and laser light energy sources are used for ionization of the gas.

\section{Devices used for plasma generation}

Devices for the production of cold plasma at or near atmospheric pressure are corona discharge, dielectric barrier discharges (DBD) or plasma jet and microwave plasma (Figure 1). Although other devices such as micro hollow cathode discharge, radio frequency plasma (RFP), gliding arc discharge, one atmospheric uniform glow discharge, dielectric plasma needle have been used for plasma production. Among all, dielectric barrier discharges (DBD) and Atmospheric Pressure Plasma Jet (APPJ) are most commonly used in the food industry (Ragni et al., 2010; Nehra et al., 2008).

\section{Dielectric Barrier Discharge (DBD)}

Two flat metal electrodes, where at least one of these electrodes is covered with a dielectric material constitute DBD. Dielectric barriers (a stabilizing material) avoid arc transition, and help in creating a large number of microdischarges for homogeneous treatments.

Plasma is created after ionization of a carrier gas by alternative current high voltages in $\mathrm{kHz}$ range (power 10-100 W) which moves between high voltage and grounded electrode.

There are variations in the configuration of the electrodes, but the concept behind them all remains the same (Hoffmann et al., 2013).It can be applied for sterilization of living tissue, bacteria inactivation, angiogenesis, surface treatment and excimer formation.

\section{Atmospheric pressure plasma jet}

\section{Radiofrequency plasma jets}

It is type of plasma jet, which is used for bacterial inactivation at atmospheric pressure, is called the Atmospheric Pressure Plasma Jet (APPJ) (Schutze et al., 1998). The APPJ consists of two coaxial electrodes between which a gas (mixtures of helium, oxygen, and other gases) is transmitted at a high speed. The outermost electrode is grounded while Radio Frequency (RF) power (50-100W) at 13.56 MHz is applied to the central electrode that creates a plasma discharge. The reactive species produced exits the nozzle at high velocity and arrives at the area that is to be treated.

APPJ has been used for the inactivation of several food born and harmful microorganisms (Herrmann et al., 1999; Abramson et al., 2006; Hong et al., 2009; Fricke et al., 2012; Niemira., 2012; Tseng et al., 2012; Alkawareek et al., 2012; Jiang et al., 2012; Matthes et al., 2012; Hoffmann et al., 2013). 


\section{Pulsed direct current-driven plasma jets}

Laroussi et al., (2006) developed a miniature jet which he named as plasma pencil (Barekzi et al., 2012).

It consists of a dielectric cylindrical tube where two disk electrodes of the same width as the tube are inserted.

The two electrodes are separated by a space (the distance can vary from 0.3 to $1 \mathrm{~cm}$ ) and consist of a thin ring of copper attached to a dielectric disk. To generate the plasma, gases are injected through the holes of the electrodes for sub-microsecond with high voltage pulses.

A plasma plume (up to $5 \mathrm{~cm}$ in length at temperature $290 \mathrm{~K}$ ) is launched through the shaft of the outer electrode into the air at the time of discharge.

The supply of electrical power through high voltage is provided by pulse generator. The plasma pencil has been used in the treatment of E. coli, Leukemia cells, and P. gingivalis (Foster et al., 2010; Mahesh et al., 2011).

Cold plasma for the safety and sustainability in the fish processing industry

The natural composition of fish and the contaminations they encounter during the processing are the leading causes for the onset and subsequent undesirable quality changes in these commodities (Mahmud et al., 2018). The spoilage mechanisms associated with microbial metabolic activities, endogenous enzymatic activities and chemical oxidation of lipids, all of shortening the shelf life of seafood. So the processing of seafood in a proper way is significant to make it suitable for the consumption for the final consumer.
Application of cold plasma on food which is at low temperatures, short processing times have been made in several processing stages such as treatment to raw material, intermediate or finished products, processing water, processing types of equipment and environment. Bourke et al., (2018) showed the therapy to be energy efficient with a high antimicrobial effect on food quality and environment (Milosavljevic et al., 2007; Bourke et al., 2018).

Zouelm et al., (2019) estimated the effects of cold plasma on chemical spoilage of pacific white shrimp (Litopenaeus vannamei) during frozen storage. Cold plasma (CP) was applied for different periods, i.e. 45, 90, and 150second as T1, T2, and T3, respectively, to freshly harvested shrimp. Post-mortem changes during cold storage reduce shelf life. The biochemical parameters and melanosis were analysed in comparison to metabisulphite treated (TM) and control sample during 12 days of frozen storage. The results showed that increase in $\mathrm{pH}$, total volatile base nitrogen (TVB-N) content, thiobarbituric acid reactive substances (TBARS), free fatty acid (FFA), and peroxide value (PV) in shrimp exposed to $\mathrm{CP}$ and metabisulphite compared to control. Albertos et al., (2017) estimated the significant effect of atmospheric cold plasma generated by a novel in-package dielectric barrier discharge (DBD) on lipid. However, effects on lipid oxidation parameters (PV, Dienes) were observed for the oxidation of the treated sample.

Nevertheless, no changes in $\mathrm{pH}$ or colour (except for $\mathrm{L}^{*}$ ) were observed. These results suggest atmospheric cold plasma generated by DBD could be implemented as a technology for fish processing, retaining product quality over its shelf life. 
Plasma-Activated Water (PAW) for chilling

Plasma-treated water (PTW) an aqueous solution which is processed with plasma and the treatment results produces a wide range of chemically active species that can be retained within the water. Plasma treatment can be applied to liquid waste from various foods processing industry for decontamination or sterilization purposes. The term plasmaactivated water is widely used for plasma medicine applications.

Liao et al., (2018) uses plasma-activated water (PAW) ice for the preservation of fresh shrimps. The changes in microbiological, physical, chemical and protein properties were investigated during storage with conventional tap water (TW) ice and PAW ice. Compared with TW ice, PAW ice showed a significant advantage for inhibition of microbial growth, extending the storage time by $4-8$ days. The $\mathrm{pH}$ of shrimps treated with PAW ice remained below 7.7 during storage. The PAW ice treatment delayed the deteriorating changes in colour characteristics and hardness. The production of volatile basic nitrogen (TVBN) was reduced to below $20 \mathrm{mg} / 100 \mathrm{~g}$ during PAW ice storage, significantly lower ( $\mathrm{p}<$ 0.05 ) than that of the samples treated with TW ice. Besides, PAW ice did not result in adverse changes in shrimp proteins. Therefore, the study showed that PAW ice might be used in the preservation of fresh seafood.

\section{Antimicrobial effect of plasma on sea food}

A minimal attempt has been made at the use of plasma technology to enhance the quality and safety of seafood. Lee et al., (2011) showed that $\mathrm{CP}$ treatment for 2 min with helium gas $(5 \mathrm{~L} / \mathrm{min})$ mixed with oxygen (100 $\mathrm{mL} / \mathrm{min}$ ) at $60 \mathrm{~Hz}$ and $30 \mathrm{kV} / \mathrm{cm}$ retarded the growth of $L$. monocytogenes in smoked salmon by $1 \log \mathrm{CFU} / \mathrm{g}$.
Chiper et al., (2011) reported that the population of Photobacterium phosphoreum, a bacterium associated with seafood spoilage in cold-smoked salmon, was significantly reduced $(<3 \log \mathrm{CFU} / \mathrm{g}$ ) by $\mathrm{CP}$ (air and air + $7 \% \mathrm{CO}_{2}$ mixture) treatments operated at an applied voltage: $13 \mathrm{kV}$ at $15 \mathrm{kHz}$ frequency for in 60 to $120 \mathrm{sec}$.

Park and Ha (2015) reported a significant decrease in the counts of Cladosporium cladosporioides and Penicillium citrinum on dried filefish fillets with increasing cold oxygen plasma (air subjected to high-energy deep-ultraviolet (UV) light with an effective radiation spectrum between 180 and $270 \mathrm{~nm}$ ) with treatment times of 3 to $20 \mathrm{~min}$.

Bacterial spores are most resistant form of life. Non-thermal atmospheric gas discharge plasma is effective sterilization methods that have very fewer disadvantages on the food quality and leaves no chemical residue. In this study, they used a helium radio-frequency cold plasma jet to examine its sporicidal effect on selected strains of gram-positive bacteria (Bacillus and Clostridium spp). The species tested included $B$. subtilis, $B$. stearothermophilus, $\mathrm{Cl}$. sporogenes, $\mathrm{Cl}$. perfringens, Cldifficile, and Clbotulinum type $\mathrm{A}$ and $\mathrm{E}$. The plasmas were useful in inactivating spores of Bacillus and Clostridia spp with $\mathrm{D}$ values ranging from 2 to $8 \mathrm{~min}$. Among all spores, $C$. botulinum type A and $C$. sporogenes were more resistant to plasma inactivation than other species.

Choi et al., (2016) studied, microbial decontamination of dried Alaska pollock shreds using corona discharge plasma jet (CDPJ). Corona plasma jet was generated at a current strength of $1.5 \mathrm{~A}$, and a span length of $25 \mathrm{~mm}$ was maintained between the electrode tip and fish sample. Upon the CDPJ treatment (0 to $3 \mathrm{~min}$ ) of dried shreds, microbial 
contaminants namely aerobic and marine bacteria, and Staphylococcus aureus were inactivated by $2.5,1.5$, and $>1.0 \mathrm{log}$ units, respectively. Also, a one-log reduction in molds and yeasts contaminants was observed.

The treatment of cold-smoked salmon packed in a sealed package, using a Dielectric-barrier discharge (DBD) plasma (operated at an applied voltage: $13 \mathrm{kV}$ at $15 \mathrm{kHz}$ frequency) in $\mathrm{Ar}$ and $\mathrm{Ar}+7 \% \mathrm{CO} 2$ mixture has been reported (Chiper et al., 2011). Up to a $3 \log$ $\mathrm{CFU} / \mathrm{g}$ decrease in the population of Photobacterium phosphoreum was observed from fish samples within 60-120 s of cold plasma treatment.

Park and Ha (2015) examine the effects of cold oxygen plasma on dried filefish fillets (Stephanole piscirrhifer) of the reductions of Cladosporium cladosporioides and Penicillium citrinumon. Their plasma source employed relied on the use of high-energy ultraviolet radiation between 180 and $270 \mathrm{~nm}$ for the ionisation. They were able to estimate the reduction in both bacteria on the treated fillets after $>10 \mathrm{~min}$ by $>1 \log \mathrm{CFU} / \mathrm{g}$

Albertos et al., (2017) estimated the effect of atmospheric cold plasma on microbial and quality parameters of mackerel fillets. Dielectric Barrier Discharge treatment, with $70 \mathrm{kV}$ and $80 \mathrm{kV}$ voltage and different treatment time (1, 3 and $5 \mathrm{~min}$ ) reduced total aerobic psychrotrophic, Pseudomonas and lactic acid bacteria) were significantly reduced.

\section{Mechanism of bacterial inactivation by cold plasma}

Inactivation of food-related microorganisms by plasma treatment is commonly conducted using model systems. An overview of microbial inactivation in model systems using nonthermal plasma published during the last three years is given by Wan et al., (2009). The antimicrobial activity of nonthermal plasma against Gram-negative and Gram-positive bacteria, yeast and fungi, biofilm formers, and endospores was shown in various studies (Brandenburg et al., 2007, Kelly-Wintenberg et al., 1999, Laroussi, 2005; Montie et al., 2000; Vleugels et al., 2005). Although several reviews focus on the inactivation mechanisms of plasma (Boudam et al., 2006; Gaunt et al., 2006; Moisan et al., 2001; Moreau et al., 2008), it is not yet fully understood. Microbial contamination has a significant economic impact in the seafood industry as it leads to product contamination, equipment damage, production downtime, energy losses, and investigations (Eissa et al., 2014). Owing to their high-level heat resistance by spores produced by certain bacteria such as Bacillus and Clostridium under unfavourable environmental conditions, various sterilization processes are designed in such a way as to include the bacterial spores in the inactivating process (Hugo and Russell, 1998; Setlow, 2013). On the other hand, the existence of fungi or molds, especially mycotoxin and antibiotics producers, in manufacturing environments causes more concern since these types of organisms spread very rapidly by forming spores that are easily transferred from one site to another (Eissa et al., 2014). Ordinarily, thermal processing is used to produce microbiologically, safe and stable food products. However, it is not a preferred method due to the loss of nutritional and sensorial qualities. This has led to the emergence of mild nonthermal decontamination technologies such as nonthermal plasma (Ekezie et al., 2017).

Moisan et al., (2001) stated that three primary mechanisms are involved in plasma inactivation to microbes: (a) ultraviolet (UV) irradiation of genetic material, i.e. damage to membranes and internal cellular components by UV radiation (b) intrinsic photodesorption, 
means chemical interaction of radicals, reactive species, or charged particles with cell membranes. (c) etching means DNA strands may be broken by UV generated during recombination of the plasma species (Moisan et al., 2002) (Figure 2).

Moreau et al., (2008) compared plasma inactivation effects to the effects of micropulse. Similar to the impact of micro pulses, the cell membranes of microorganisms are perforated after plasma treatment. Besides the perforation of the cell membrane, the inactivation effect of plasma is induced by the bombardment of the cell membrane by radicals $(\mathrm{OH}$ or $\mathrm{NO})$. These radicals are absorbed onto the bacteria surface, and volatile components are formed and eliminated from the cells (etching).

Two mechanisms of plasma inactivation, also described by Gaunt et al., (2006) are the electrostatic disruption of cell membranes and lethal oxidation of cellular components.

While on a given commodity, one mode of action may be more significant than another, the most excellent sanitizing efficacy results from plasma with multiple antimicrobial mechanisms (Moisan et al., 2002; Laroussi, 2002; Niemira, 2012). Lee et al., (2011) estimated the effects of nonthermal plasma treatments against Salmonella typhimurium, Escherichia coli O157: H7, and Listeria monocytogenes living on polystyrene (PS), sausage casings, and smoked salmon were investigated. Inoculated PS, casings, and salmon were treated with nonthermal plasma generated with helium $(5 \mathrm{~L} / \mathrm{min})$ or with both helium $(5 \mathrm{~L} / \mathrm{min})$ and oxygen $(100 \mathrm{~mL} / \mathrm{min})$ at $60 \mathrm{~Hz}$ and $30 \mathrm{kV} / \mathrm{cm}$ for 2,5 , or $10 \mathrm{~min}$. $S$. typhimurium exhibited the highest sensitivity to the helium-used treatment. The most considerable reduction $(3.9 \pm 0.8 \log \mathrm{CFU} / \mathrm{cm} 2)$ was observed with L. monocytogenes on PS after the treatment with the mixed gas for 5 min. The treatment with the mixed gas inhibited L. monocytogenes on casings and salmon by $0.5 \pm 0.3 \log \mathrm{CFU} / \mathrm{cm} 2$ and $1.0 \pm 0.3$ $\log \mathrm{CFU} / \mathrm{g}$, respectively. Different treatment times did not result in different reductions of L. monocytogenes on both casings and salmon. The types of treatment gas and material of contamination need to be considered for evaluating the antimicrobial effects of nonthermal plasma treatments.

\section{Plasma effect on the nutritional quality of seafood}

\section{Effect on protein}

Protein can be denatured by the activity of cold plasma reactive species with amino acids and loss in the secondary structure due to injury of $\alpha$-helix and $\beta$-sheet (Li et al., 2014; Segat et al., 2016)

The effects of CP were studied on the muscle of raw mackerel, where it resulted in a decrease in immobilized water located in the protein-dense myofibrillar network (Albertos et al., 2017).

Chen et al.,(2019) analyses effect of cold plasma on the microstructure of chub mackerel (Scomber japonicus) fillets. He was able to find that microstructure of the fillet of the Atmospheric cold plasma (ACP) treated and untreated chub mackerel was observed through a scanning electron microscope (SEM). The myofibrils and intramuscular connective tissues in the microstructures of the untreated samples differed from those of the treated samples. The muscle of the fresh fish displayed a bright and dense myofibril structure. No evident cracks appeared in the intramuscular connective tissues of the raw samples. Similarly, the ACP-pretreated samples maintained their regular and dense myofibril structure after six days of storage. The connective tissues were tightly connected. 
On the contrary, the batch without the ACP pretreatment was characterized by loose myofibril structure and marked ruptures after six days of storage, indicating microstructure deterioration. The occurrence of breakdowns was probably due to the degradation of myofibrillar protein, which constitutes intramuscular connective tissues.

\section{Impact on enzymes}

Enzymes as biocatalysts are widely applied to the food industry to improve the biochemistry reaction rates. Endogenous enzymes are naturally present in foods display either desirable or undesirable impacts on texture, colour and flavour of foods during food processing or preservation (Pasquali et al., 2016; Zhang et al., 2018). The sufficient inactivation of enzymes in foods is also necessary to advance our quest to develop cold plasma technology which could genuinely compete with thermal processing methods. The studies reported in the literature point to changes in the protein structure at multiple scales ranging from amino acids, specific linkages and the secondary structures. The plasma-induced changes in enzyme's activity depend on the environment, i.e. whether it is a simple buffered medium or a complex food extract, in addition to the parameters of the plasma process itself.

Dudak et al., (2007) found a decrease of enzyme activity after treatment with plasma generated in Radio frequency driven glow discharge with the highest decline in operation within the first 10 minutes of treatment. They showed plasma-chemical oxidation as well as fragmentation of the proteins. Additionally, changes in the secondary protein structure due to the plasma treatment were detected. A fragmentation of proteins was also found by Deng et al., (2007) after DBD treatment. In this process, atomic oxygen was shown to play a dominant role in destruction and degradation reactions. Oxygen plasma generated by RF discharge led to a reduction of $\mathrm{C}-\mathrm{H}$ and $\mathrm{N}-\mathrm{H}$ bonds in casein protein and a modification of the secondary protein structure (Hayashi et al., 2009).

Cold plasma has been reported to inactivate a range of enzymes such as lysozyme (Takai et al., 2012), polyphenol oxidase and peroxidase (Pankaj et al., 2013; Surowsky et al., 2013; Tappi et al., 2014).

Peroxidase (POD) and polyphenol oxidase (PPO) are essential enzymes which are responsible for melanosis in shellfishes, especially in shrimp. Peroxidases are often associated with reactions which could adversely influence food quality such as lipid and phenolic oxidations with consequent deterioration of flavour and colour. Mishra et al., (2016) found that these enzymes are also important in vegetables and PPO catalyzes the hydroxylation of monophenols to o-diphenols and the oxidation of o-diphenols to the oquinones.

The study by Surowsky et al., (2013) shows that: non-thermal atmospheric pressure plasma is capable of reducing the activity of polyphenol oxidase and peroxidase The inactivation efficiency depends on the plasma exposure time and gas composition; which leads to losses of the enzymes helical structure; and the active components inherent to the plasma are solely responsible for enzyme inactivation.

Zouelm et al., (2019) estimated the effects of cold plasma on quality of endogenous enzymes polyphenol oxidase (PPO) enzyme, of pacific white shrimp (Litopenaeus vannamei) during refrigerated storage. Cold plasma was applied for 45, 90, and 150s as T1, $\mathrm{T} 2$, and $\mathrm{T} 3$, respectively, to freshly harvested shrimp. Results demonstrate that CP exposure effectively decreases the activity of polyphenol oxidase (PPO) enzyme, and prolonging the exposure to $\mathrm{CP}$ for $150 \mathrm{~s}$ 
resulted in a 50\% reduction in enzyme activity. They concluded that the application of $\mathrm{CP}$ for $90 \mathrm{~s}$ was the most efficient circumstance to extend the shelf life of white shrimp during cold storage.

A recent study was done by Ali et al., (2016) on inactivation of tyrosinase by giving an exposure to plasma-treated eugenol derivatives. The plasma treatment was hypothesized to increase the functional groups in eugenol derivatives, which increase the interactions between the new compounds and tyrosinase. The authors also observed a change in the secondary structure of the enzyme by circular dichroism spectroscopy, on exposure to the derivatives. Plasma treatments have been shown to enhance the antibacterial activity of plant essential oils in food systems (Matan et al., 2014a; Matan et al., 2014b). However, the synergistic action on food enzymes remains unreported and is likely to have a positive impact.

Cold plasma is a promising, economic and environmentally friendly technology that exhibits the ability to inactivate endogenous enzymes activities such as PPO, POD and LOX in liquid or solid food systems, while the actions of a-amylase and some antioxidase including SOD, CAT in an organism can be increased by applying cold plasma (Han et al., 2019).

\section{Effect on carbohydrates}

Carbohydrates play an essential role in defining and maintaining the quality of different food products. Seafood consists of a meagre amount of carbohydrate

Rodríguez et al., (2017) reported an increase in sucrose content after prolonged exposure to $\mathrm{CP}$, due to degradation of the oligosaccharides with a high degree of polymerization. A similar decrease in the fructose was also reported after $\mathrm{CP}$ treatment of prebiotic orange juice (Almeida et al., 2015). The studies suggest ozonolysis degradation causing the breakdown of glycoside bonds, leading to depolymerization of the macromolecule and the oxidation of functional groups to form carbonyl and carboxyl compounds, lactones, hydroperoxides and $\mathrm{CO}_{2}$ (Ben'ko et al., 2013; Almeida et al., 2015).

$\mathrm{CP}$ alter the configuration of starch molecules, leading to transformation in swelling power, pasting characteristics, water absorption, enzyme susceptibility, solubility and changes in compositional, structural and thermal properties (Thirumdas et al., 2017; Wu et al., 2018).

Typically, these modifications are initiated via an increase in surface energy, incorporation of functional groups, cross-linking, depolymerization and change in hydrophilic nature (Thirumdas et al., 2017).

\section{Application of cold plasma in packaging}

Cold plasma technology is one of the advanced food processing technologies which find widespread potential as surface modification technique in the field of food packaging (Pahwa and Kumar, 2018). Cold plasma (CP) induces several chemical and physical processes in the plasma volume and on the plasma polymer interface, which modify the surface properties. This phenomenon is exploited in surface functionalisation to impart selective and tunable surface energies to the packaging polymers for promoting adhesion or sometimes anti-adhesion (Poncin-Epaillard et al., 1999), improved printability, sealability, imparting animist properties and improving the polymer's resistance to mechanical failure. Packaging materials barrier properties towards gases (oxygen, carbon dioxide) and chemical solvents can be enhanced by using plasma deposition of barrier layers (Schneider et al., 2009). A gas plasma reaction efficiently 
inactivates polymer surface adheredmicroorganisms (bacterial cells, spores, yeasts and moulds) within short treatment times. Muranyi et al., (2007) established that packaging materials such as plastic bottles, lids and films can be rapidly sterilised using cold plasma, without adversely affecting their bulk properties or leaving any residues.
The plasma process is a simultaneous deposition/ removing process in which loosely deposited species over planar or topographical surfaces are sputtered off by reactive ions and radicals during deposition. However, it was shown that in some cases, UV photons could play a role in the inactivation process of microorganisms at atmospheric pressure (Boudam et al., 2006).

Atmospheric plasma: Characteristics and classification

\begin{tabular}{|c|c|c|c|}
\hline Properties & $\begin{array}{l}\text { Local thermodynamic } \\
\text { equilibrium plasmas } \\
\text { (LTE)/ (Quasi- } \\
\text { equilibrium plasma) }\end{array}$ & $\begin{array}{l}\text { Non Local } \\
\text { thermodynamic } \\
\text { equilibrium } \\
\text { plasmas (non- LTE) }\end{array}$ & References \\
\hline Current name & Thermal plasma & Cold plasma & Tendero et al., 2006 \\
\hline Temperature & $\mathrm{T}_{\mathrm{e}}=\mathrm{T}_{\mathrm{h}} 10,000 \mathrm{~K}$ & $\begin{array}{l}\mathrm{T}_{\mathrm{e}}=10,000-100,000 \mathrm{~K} \\
\mathrm{~T}_{\mathrm{h}} 300-1000 \mathrm{~K}\end{array}$ & $\begin{array}{l}\text { Tendero et al., 2006; } \\
\text { Misra } \text { et al., } 2016\end{array}$ \\
\hline Pressure & High pressure, $105 \mathrm{pa}$ & Low pressure, $10 \mathrm{pa}$ & Scholtz et al., 2015 \\
\hline Density & High electron density & Lower electron density & Tendero et al., 2006 \\
\hline $\begin{array}{l}\text { Energy } \\
\text { Electrons }\end{array}$ & $\begin{array}{l}\text { Consumed by heavy } \\
\text { particles }\left(\mathrm{T}_{\mathrm{e}}=\mathrm{T}_{\mathrm{h}}\right)\end{array}$ & $\operatorname{Very} \operatorname{High}\left(\mathrm{T}_{\mathrm{e}}>>\mathrm{T}_{\mathrm{h}}\right)$ & Tendero et al., 2006 \\
\hline Constituents & $\begin{array}{l}\text { electrons, positive and } \\
\text { negative ions, free } \\
\text { radicals, and gas atoms, } \\
\text { molecules }\end{array}$ & $\begin{array}{l}\text { electrons, positive and } \\
\text { negative ions, free } \\
\text { radicals, and gas atoms, } \\
\text { molecules }\end{array}$ & Tendero et al., 2006 \\
\hline State & Excited/ionized & Excited & Tendero et al., 2006 \\
\hline Example & Arc plasma & Glow discharges & $\begin{array}{l}\text { Afshari and Hosseini., } \\
2012\end{array}$ \\
\hline
\end{tabular}

Whereas $T_{e}-$ Temperature of electron and $T_{h}$ - Temperature of heavy particles

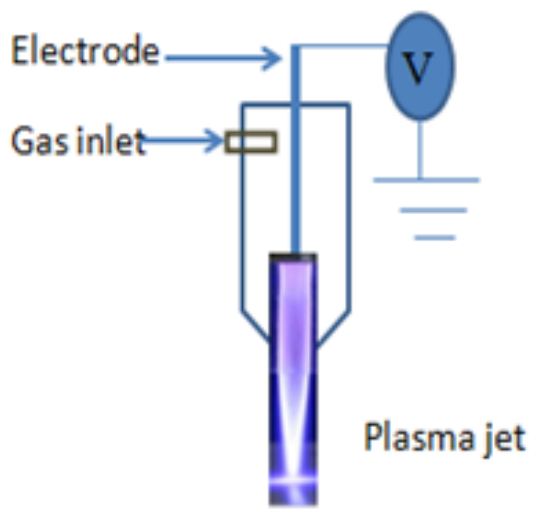

Figure 1. Devices used for production of atmospheric plasma a) Plasmajet system; b) Dielectric

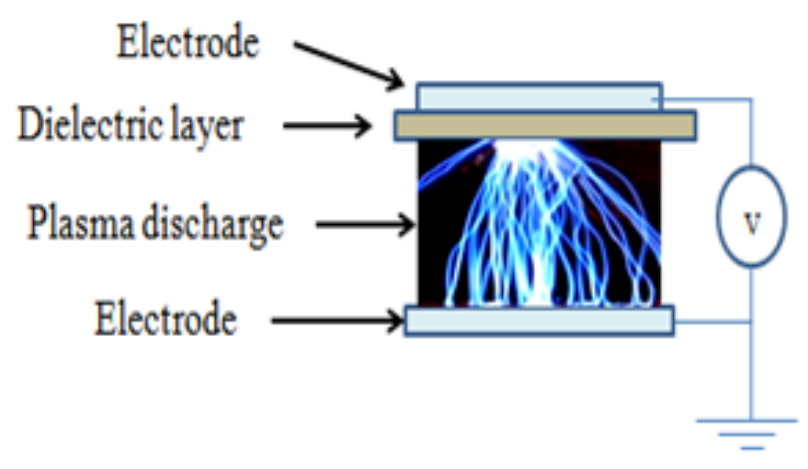

bamier discharge 


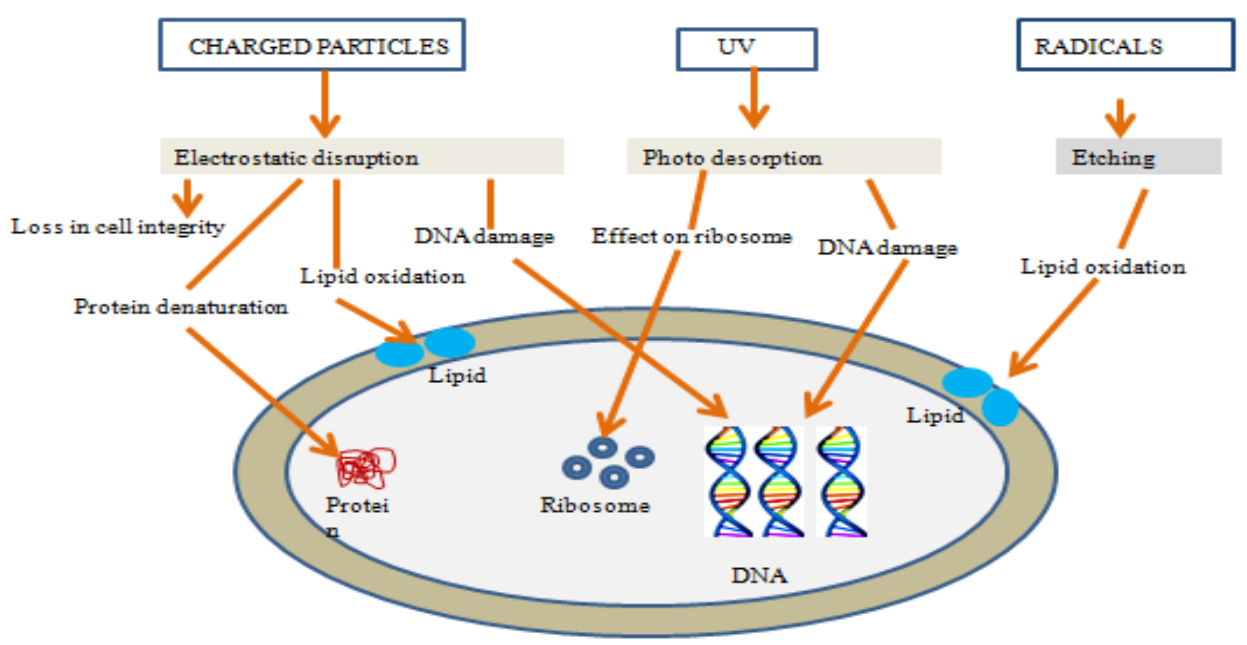

Figure 2. Schematic overview of cold atmospheric pressure plasma (CAPP) on inactivationmechanisms of bacterial cell

\section{Antioxidant activity of cold plasma}

Antioxidants are considered as the first line of defence against free radicals. It is therefore of particular interest to elucidate and understand the fundamental interactions of plasma species with bioactive compounds, to avoid nutritional degradation or any other undesired effects in future applications. Antioxidants protect cells against the damaging effects of ROS (Reactive oxygen species), such as singlet oxygen, superoxide, peroxyl radicals, hydroxyl ions and peroxynitrite etc. (Percival, 1996). There are only a few literatures available on the effect of plasma treatment on the phenolic compounds. Harborne and Williams (2000), reported that several plant species are tolerant to UV radiations accumulating flavonoid metabolites in epidermal cells. During plasma generation, the UV radiations formed may be responsible for the formation of phenolic compounds which are extracted from the cells of upper epidermis of leaves.

Ozone, atomic oxygen, UV radiations, photons, chemically reactive species, and charged particles generated in plasma are the active oxidising agents which are responsible to affect the stability of microbial cell membranes and spawn the antimicrobial effect (Kelly-Wintenberg et al., 1999; Brandenburg et al., 2007; Perni et al., 2008; Frohling et al., 2012)

Seafood are rich in both polyunsaturated and saturated fats, which are much prone to oxidation during various processing methods. $\mathrm{CP}$ can decontaminate agricultural food products, Dairy products, meat products and poultry products in the food processing industry (Deng et al., 2007).

Depending on the plasma sources, type of gases used, processing methods, and the concentrations of reactive species have different effect vary with various microbes.

Also, the different plasma devices have different inactivation kinetics regarding microbial cell (Frohling et al., 2012). Atomic oxygen-reactive species can attach the bacterial cell wall, which makes them more prone to attack and lead to cell destruction (Critzer et al., 2007). Oxidation of nucleic acids and amino acids also can cause changes in its fundamental properties, which can lead 
damage to microorganism (Smeu and Nicolau, 2014).

\section{Limitation of cold plasma technology}

Treatment with CP can induce lipid oxidation in fatty foods and other food products susceptible to oxidation. This may lead to the creation of short-chain fatty acids, aldehydes, hydroxyl acids, and keto acids, thus causing off-flavours and off-odours during storage (Ekezie et al., 2017). Undesirable textural properties, acidity, and discolouration of treated food can occur. Also, surface topography can be influenced by plasma treatment (Fernandez-Gutierrez et al., 2010). The high cost of installation is also a major drawback.

Currently, available data reveals that cold plasma technology could be utilised as a novel antimicrobial intervention for the inactivation of pathogens and improvement of the safety of foods of animal origin. However, studies performed to date also show certain limitations of cold plasma treatment in foods of animal origin, such as the acceleration of lipid oxidation and a negative impact on sensory characteristics. Further research is required to find out the effects of cold plasma on a broad range of quality aspects, including the sensory characteristics of various foods of animal origin, and the retention of these aspects during storage. Furthermore, the impact of cold plasma on the nutritional value of meat, eggs, fish, and their products requires comprehensive investigations. Additionally, the analysis of the marketability/consumer acceptance of cold plasma treated foods of animal origin is crucial, because the potential value of novel food technologies can only be realised if their application does not negatively affect the consumers' purchase decision making. In the past decade, CP treatment of food products has experienced increased popularity due to its potential contribution to non-thermal food processing. Several experimental investigations have been conducted thus far on known applications while others explored new pathways for the exploitation of non-thermal plasma for the food industry.

Therefore, this review is a collation of recent studies focused on the applications of cold plasma in the food industry including microbial decontamination of food products, packaging material processing, modification of food components, seed germination performance and degradation of agrochemical residues. The review also highlights other trajectories for CP employment in the food industry such as hydrogenation of oils, mitigation of food allergens and antinutritional factors and effluent management. In consideration of the preceding, it should be safe to conclude that $\mathrm{CP}$ technology holds potential significance for the food industry.

\section{References}

Abramzon N, Joaquin JC, Bray J, Brelles-Marino G (2006) Biofilm destruction by RF highpressure cold plasma jet. IEEE Trans Plasma Sci., 34(4):1304-1309

Afshari, R., and Hosseini, H. (2012). Atmospheric pressure plasma technology: a new tool for food preservation. In International Conference on Environment, Energy and Biotechnology. Singapore: IPCBEE (pp. 275-8).

Albertos, I., Martín-Diana, A. B., Cullen, P. J., Tiwari, B. K., Ojha, S. K., Bourke, P., and Rico, D. (2017). Effects of dielectric barrier discharge (DBD) generated plasma on microbial reduction and quality parameters of fresh mackerel (Scombers combrus) fillets. Innovative Food Science and Emerging Technologies, 44, 117-122.

Ali, A., Ashraf, Z., Kumar, N., Rafiq, M., Jabeen, F., Park, J. H., and Attri, P. (2016). Influence of plasma-activated compounds on melanogenesis and tyrosinase activity. Scientific reports, 6, 21779.

Alkawareek MY, Algwari QT, Gorman SP, Graham WG, O'Connell D, et al., (2012) Application 
of atmospheric pressure nonthermal plasma for the in vitro eradication of bacterial biofilms. FEMS Immunol Med Microbiol, 65:381-384.

Almeida, F. D. L., Cavalcante, R. S., Cullen, P. J., Frias, J. M., Bourke, P., Fernandes, F. A., and Rodrigues, S. (2015). Effects of atmospheric cold plasma and ozone on prebiotic orange juice. Innovative food science and emerging technologies, 32, 127135.

Barekzi, N., and Laroussi, M. (2012). Dosedependent killing of leukaemia cells by lowtemperature plasma. Journal of Physics D: Applied Physics, 45(42), 422002.

Ben'ko, E. M., Manisova, O. R., \&Lunin, V. V. (2013). Effect of ozonation on the reactivity of lignocellulose substrates in enzymatic hydrolyses to sugars. Russian Journal of Physical Chemistry A, 87(7), 1108-1113.

Birwal, P., Deshmukh, G.P. and Ravindra, M.R.(2019). Nonthermal Processing of Dairy Beverages. In Milk-Based Beverages (pp. 397-426). Woodhead Publishing.

Boudam, M. K., Moisan, M., Saoudi, B., Popovici, C., Gherardi, N., and Massines, F. (2006). Bacterial spore inactivation by atmosphericpressure plasmas in the presence or absence of UV photons as obtained with the same gas mixture. Journal of Physics D: Applied Physics, 39(16), 3494.

Bourke, P., Ziuzina, D., Boehm, D., Cullen, P. J., and Keener, K. (2018). The potential of cold plasma for safe and sustainable food production. Trends in Biotechnology, 36(6), 615-626.

Brandenburg, R., Ehlbeck, J., Stieber, M., v. Woedtke, T., Zeymer, J., Schlüter, O., and Weltmann, K. D. (2007). Antimicrobial treatment of heat-sensitive materials by means of atmospheric pressure Rf-driven plasma jet. Contributions to Plasma Physics, 47(1-2), 72-79.

Chen, J., Wang, S. Z., Chen, J. Y., Chen, D. Z., Deng, S. G., and Xu, B. (2019). Effect of cold plasma on maintaining the quality of chub mackerel (Scomberjaponicus): biochemical and sensory attributes. Journal of the Science of Food and Agriculture, 99(1), 39-46.

Chiper, A. S., Chen, W., Mejlholm, O., Dalgaard, P., and Stamate, E. (2011). Atmospheric pressure plasma produced inside a closed package by a dielectric barrier discharge in $\mathrm{Ar} / \mathrm{CO} 2$ for bacterial inactivation of biological samples. Plasma Sources Science and Technology, 20(2), 025008.

Choi, S., Puligundla, P., and Mok, C. (2016). Microbial decontamination of dried Alaska pollock shreds using corona discharge plasma jet: effects on physicochemical and sensory characteristics. Journal of Food Science, 81(4), M952-M957.

Critzer, F. J., Kelly-Wintenberg, K., South, S. L., and Golden, D. A. (2007). Atmospheric plasma inactivation of foodborne pathogens on fresh produce surfaces. Journal of food protection, 70(10), 2290-2296.

Deng, X. T., Shi, J. J., Chen, H. L., and Kong, M. G. (2007). Protein destruction by atmospheric pressure glow discharges. Applied physics letters, 90(1), 013903.

Dudak, F. C., Kousal, J., Seker, U. O. S., Boyaci, I. H., Choukourov, A., and Biederman, H. (2007). Influence of the plasma treatment on enzyme structure and activity. Proc. 28th ICPIG, Prague, Pp. 15-20.

Eissa, M. E., El Naby, M. A., \&Beshir, M. M. (2014). Bacterial vs fungal spore resistance to peroxygen biocide on inanimate surfaces. Bulletin of Faculty of Pharmacy, Cairo University, 52(2), 219-224.

Ekezie, F. G. C., Sun, D. W., and Cheng, J. H. (2017). A review on recent advances in cold plasma technology for the food industry: Current applications and future trends. Trends in Food Science and Technology, 69, 46-58.

Erkan, N., G. Üretener, H. Alpas, A. Selçuk, Ö. Özden and S. Buzrul. (2011). The effect of different high-pressure conditions on the quality and shelf life of cold-smoked fish. Innovative Food Science and Emerging Technologies 12(2): 104-10

Fernandez-Gutierrez, S. A., Pedrow, P. D., Pitts, M. J., and Powers, J. (2010). Cold atmosphericpressure plasmas applied to active packaging of apples. IEEE Transactions on Plasma Science, 38(4), 957-965.

Foster JE, Weatherford B, Gillman E, Yee B: Underwater operation of a DBD plasma jet. Plasma Sources Sci T 2010, 19(2): 025001.

Fricke K, Koban I, Tresp H, Jablonowski L, Schröder K, Kramer A, Weltmann K-D, von Woedtke T, Kocher T.(2012). Atmospheric pressure plasma: a high-performance tool for 
the efficient removal of biofilms. PLOS ONE, 7(8):e42539. DOI:10.1371/journal.pone.0042539.

Fridman, A., Chirokov, A., and Gutsol, A. (2005). Non-thermal atmospheric pressure discharges. Journal of Physics D: Applied Physics, 38(2), R1.

Fröhling, A., Baier, M., Ehlbeck, J., Knorr, D., and Schlüter, O. (2012). Atmospheric pressure plasma treatment of Listeria innocua and Escherichia coli at polysaccharide surfaces: Inactivation kinetics and flow cytometric characterization. Innovative food science and emerging technologies, 13, 142-150.

Ganan, M., E. Hierro, X. F. Hospital, E. Barroso, and M. Fernández. (2013). Use of pulsed light to increase the safety of ready-to-eat cured meat products. Food Control 32(2):512-7

Gaunt, L. F., Beggs, C. B., \&Georghiou, G. E. (2006). Bactericidal action of the reactive species produced by gas-discharge nonthermal plasma at atmospheric pressure: a review. IEEE Transactions on Plasma Science, 34(4), 1257-1269.

Gomez-Lopez, V. M., Devlieghere, F., Bonduelle, V., and Debevere, J. (2005). Intense light pulses decontamination of minimally processed vegetables and their shelf-life. International Journal of Food Microbiology, 103(1), 79-89.

Han, Y., Cheng, J. H., and Sun, D. W. (2019). Activities and conformation changes of food enzymes induced by cold plasma: A review. Critical reviews in food science and nutrition, 59(5), 794-811.

Harborne, J. B., and Williams, C. A. (2000). Advances in flavonoid research since 1992. Phytochemistry, 55(6), 481-504

Hayashi, N., Kawaguchi, R., and Liu, H. (2009). Treatment of protein using oxygen plasma produced by RF discharge. Journal of Plasma and Fusion Research Series, 8, 552555.

Herrmann HW, Henins I, Park J, Selwyn GS: Decontamination of chemical and biological warfare (CBW) agents using an atmospheric pressure plasma jet (APPJ). Phys Plasmas 1999, 6:2284.

Hoffmann, C., Berganza, C., and Zhang, J. (2013). Cold Atmospheric Plasma: methods of production and application in dentistry and oncology. Medical gas research, 3(1), 21.
Hong YF, Kang JG, Lee HY, Uhm HS, Moon E, Park YH: Sterilization effect of atmospheric plasma on Escherichia coli and Bacillus subtilis endospores. LettApplMicrobiol 2009, 48(1):33-37.

Hugo WB, Russell AD (1998) Chemical disinfectants, antiseptics and preservatives. In: Denyer SP, Hodges N, Gorman SP (eds) Hugo and Russell's pharmaceutical microbiology, 6th edn. Blackwell Science Ltd, Oxford, pp 201-228

Jiang C, Schaudinn C, Jaramillo DE, Webster P, Costerton JW: In vitro antimicrobial effect of a cold plasma jet against Enterococcus faecalis biofilms. ISRN Dentistry 2012, 2012:295736

Kelly-Wintenberg, K., Hodge, A., Montie, T. C., Deleanu, L., Sherman, D., Reece Roth, J., and Wadsworth, L. (1999). Use of a oneatmosphere uniform glow discharge plasma to kill a broad spectrum of microorganisms. Journal of Vacuum Science and Technology A: Vacuum, Surfaces, and Films, 17(4), $1539-1544$.

Laroussi, M. (2002). Nonthermal decontamination of biological media by atmospheric-pressure plasmas: review, analysis, and prospects. IEEE Transactions on plasma science, 30(4), 1409-1415.

Laroussi, M. (2005). Low-temperature plasma-based sterilization: overview and state-of-the-art. Plasma processes and polymers, 2(5), 391400.

Laroussi, M., Tendero, C., Lu, X., Alla, S., and Hynes, W. L. (2006). Inactivation of bacteria by the plasma pencil. Plasma Processes and Polymers, 3(6-7), 470-473.

Lee, H. B., Noh, Y. E., Yang, H. J., and Min, S. C. (2011). Inhibition of foodborne pathogens on polystyrene, sausage casings, and smoked salmon using nonthermal plasma treatments. Korean Journal of Food Science and Technology, 43(4), 513-517.

Li, Y.; Kojtari, A.; Friedman, G.; Brooks, A.D.; Fridman, A.; Ji, H.-F. (2014). Decomposition of L-valine under nonthermal dielectric barrier discharge plasma. J. Phys. Chem. B, $118,1612-1620$.

Liao, X., Su, Y., Liu, D., Chen, S., Hu, Y., Ye, X., and Ding, T. (2018). Application of atmospheric cold plasma-activated water (PAW) ice for preservation of shrimps 
(Metapenaeusensis). Food control, 94, 307314.

Lieberman, M. A., and Lichtenberg, A. J. (2005). Principles of plasma discharges and materials processing. John Wiley and Sons.

M. Percival, Antioxidants: Advanced Nutrition Publications Inc. (1996), 1/96 Rev. 10/98

Mahesh A, Darby M, Tolle SL, Hynes W, Laroussi M, Karakas E: Inactivation of Porphyromonasgingivalis by lowtemperature atmospheric pressure plasma. Plasma Med 2011, 1(3-4):191-204.

Mahmud, A., Abraha, B., and Samuel, M. (2018). Fish preservation: a multi-dimensional approach. MOJ Food Process Technol, 6(3), 303-310.

Matan, N., Nisoa, M., \&Matan, N. (2014a). Antibacterial activity of essential oils and their main components enhanced by atmospheric RF plasma. Food control, 39, 97-99.

Matan, N., Nisoa, M., Matan, N., \&Aewsiri, T. (2014b). Effect of cold atmospheric plasma on antifungal activities of clove oil and eugenol against molds on areca palm (Areca catechu) leaf sheath. International Biodeterioration\& Biodegradation, 86, 196201.

Matthes R, Bekeschus S, Bender C, Hübner N-O, Kramer A. (2012). Pilot-study on the influence of carrier gas and plasma application (open resp. delimited) modifications on physical plasma and its antimicrobial effect against Pseudomonas aeruginosa and Staphylococcus aureus. GMS KrankenhaushygieneInterdisziplinär, 7(1): Doc02. DOI:10.3205/dgkh000186.

Mcdonnell, C. K., P. Allen, F. S. Chardonnereau, J. M. Arimi, and J. G. Lyng.(2014). The use of pulsed electric fields for accelerating the salting of pork. LWT-Food Science and Technology 59(2):1054-60.

Milosavljević, V., Karkari, S. K., \&Ellingboe, A. R. (2007). Characterization of the pulse plasma source. Plasma Sources Science and Technology, 16(2), 304.

Mir, S. A., Shah, M. A., and Mir, M. M. (2016). Understanding the role of plasma technology in the food industry. Food and Bioprocess Technology, 9(5), 734-750.

Mir, S. A., Shah, M. A., and Mir, M. M. (2016). Understanding the role of plasma technology in the food industry. Food and Bioprocess Technology, 9(5), 734-750.

Misra, N. N., Pankaj, S. K., Segat, A., and Ishikawa, K. (2016). Cold plasma interactions with enzymes in foods and model systems. Trends in Food Science and Technology, 55, 39-47.

Misra, N. N., Tiwari, B. K., Raghavarao, K. S. M. S., and Cullen, P. J. (2011). Nonthermal plasma inactivation of food-borne pathogens. Food Engineering Reviews, 3(3-4), 159-170.

Moisan, M., Barbeau, J., Crevier, M. C., Pelletier, J., Philip, N., and Saoudi, B. (2002). Plasma sterilization. Methods and mechanisms. Pure and applied chemistry, 74(3), 349-358.

Moisan, M., Barbeau, J., Moreau, S., Pelletier, J., Tabrizian, M., and Yahia, L. H. (2001). Lowtemperature sterilization using gas plasmas: a review of the experiments and an analysis of the inactivation mechanisms. International Journal of Pharmaceutics, 226(1-2), 1-21.

Montie, T. C., Kelly-Wintenberg, K., and Roth, J. R. (2000). An overview of research using the one atmosphere uniform glow discharge plasma (OAUGDP) for sterilization of surfaces and materials. IEEE Transactions on plasma science, 28(1), 41-50.

Moreau, M., Orange, N., \&Feuilloley, M. G. J. (2008). Non-thermal plasma technologies: new tools for bio-decontamination. Biotechnology advances, 26(6), 610-617.

Mudgil, D., and Mudgil, S. B. (2019). Objective Food Science and Technology. Scientific Publishers.

Muranyi, P., Wunderlich, J., and Heise, M. (2007). Sterilization efficiency of a cascaded dielectric barrier discharge. Journal of applied microbiology, 103(5), 1535-1544.

Murray, J., and Burt, J. R. (2001). The composition of fish. Ministry of technology Torry advisory note No. 38 .

Nehra, V., Kumar, A. and Dwivedi, H. Atmospheric non-thermal plasma sources. International Journal of Engineering (IJE), 2, 1 2008), 53.

Niemira BA: Cold plasma reduction of Salmonella and Escherichia coli $\mathrm{O} 157$ : $\mathrm{H} 7$ on almonds using ambient pressure gases. J Food Sci 2012, 77(3): M171-M175.

Niemira, B. A. (2012). Cold plasma decontamination of foods. Annual review of food science and technology, 3, 125-142.

Niemira, B. A., and Gutsol, A. (2011). Nonthermal plasma as a novel food processing 
technology. In Nonthermal processing technologies for food (pp. 272-288). Wiley.

Okpala, C. O. R., 2014. Investigation of quality attributes of ice-stored pacific white shrimp (Litopenaeus vannamei) as affected by subsequent minimal ozone treatment. LWTFood Science and Technology 57(2):538-47.

PahwaAkanksha and Kumar Honey, Influence of cold plasma technology on food packaging materials: A review 2018; International Journal of Chemical Studies; 6(2): 594-603

Pankaj, S. K., Misra, N. N., and Cullen, P. J. (2013). Kinetics of tomato peroxidase inactivation by atmospheric pressure cold plasma based on dielectric barrier discharge. Innovative Food Science and Emerging Technologies, 19, 153-157.

Pankaj, S., Wan, Z., and Keener, K. (2018). Effects of cold plasma on food quality: A review. Foods, 7(1), 4.

Park, S. Y. and Ha, S.D. (2015). Application of cold oxygen plasma for the reduction of Cladosporium cladosporioides and Penicillium citrinum on the surface of dried filefish (Stephanolepis cirrhifer) fillets. International Journal of Food Science and Technology, 50(4), 966-973.

Pasquali, F., Stratakos, A. C., Koidis, A., Berardinelli, A., Cevoli, C., Ragni, L.,...\&Trevisani, M. (2016). Atmospheric cold plasma process for vegetable leaf decontamination: A feasibility study on radicchio (red chicory, Cichoriumintybus L.). Food Control, 60, 552-559.

Perni, S., Liu, D. W., Shama, G., and Kong, M. G. (2008). Cold atmospheric plasma decontamination of the pericarps of fruit. Journal of food protection, 71(2), 302-308.

Poncin-Epaillard, F., Brosse, J. C., and Falher, T. (1999). Reactivity of surface groups formed onto a plasma-treated poly (propylene) film. Macromolecular Chemistry and Physics, 200(5), 989-996.

Ragni, L., Berardinelli, A., Vannini, L., Montanari, C., Sirri, F., Guerzoni, M. E., and Guarnieri, A. (2010). Non-thermal atmospheric gas plasma device for surface decontamination of shell eggs. Journal of Food Engineering, 100(1), 125-132.

Ramazzina, I., Berardinelli, A., Rizzi, F., Tappi, S., Ragni, L., Sacchetti, G., and Rocculi, P. (2015). Effect of cold plasma treatment on Physico-chemical parameters and antioxidant activity of minimally processed kiwifruit. Postharvest Biology and Technology, 107, 55-65.

Rode, T. M., and M. B. Hovda. 2016. High-pressure processing extends the shelf life of fresh salmon, cod and mackerel. Food Control 70: $242-8$.

Rodríguez, Ó., Gomes, W. F., Rodrigues, S., and Fernandes, F. A. (2017). Effect of indirect cold plasma treatment on cashew apple juice (Anacardium occidentale L.). LWT, 84, 457463.

Schneider, J., Akbar, M. I., Dutroncy, J., Kiesler, D., Leins, M., Schulz, A., and Stroth, U. (2009). Silicon oxide barrier coatings deposited on polymer materials for applications in the food packaging industry. Plasma Processes and Polymers, 6(S1), S700-S704.

Scholtz, V., Pazlarova, J., Souskova, H., Khun, J., and Julak, J. (2015). Nonthermal plasma-a tool for decontamination and disinfection. Biotechnology advances, 33(6), 1108-1119.

Schutze, A., Jeong, J. Y., Babayan, S. E., Park, J., Selwyn, G. S., and Hicks, R. F. (1998). The atmospheric-pressure plasma jet: a review and comparison to other plasma sources. IEEE transactions on plasma science, 26(6), 1685-1694.

Segat, A., Misra, N. N., Cullen, P. J., and Innocente, N. (2016). Effect of atmospheric pressure cold plasma (ACP) on activity and structure of alkaline phosphatase. Food and Bioproducts Processing, 98, 181-188.

Setlow P (2013) Resistance of bacterial spores to chemical agents. In: Fraise AP, Maillard JY, Sattar SA (eds) Russell, Hugo and Ayliffe's: principles and practice of disinfection, preservation and sterilization. WileyBlackwell, Oxford, pp 121-130

Simoncicova, J., Kaliňáková, B., Kováčik, D., Medvecká, V., Lakatoš, B., Kryštofová, S., and Zahoranová, A. (2018). Cold plasma treatment triggers antioxidative defence system and induces changes in hyphal surface and subcellular structures of Aspergillus flavus. Applied microbiology and biotechnology, 102(15), 6647-6658.

Smeu, I., and Nicolau, A. I. (2014). Enhancement of food safety-antimicrobial effectiveness of cold plasma treatments. The Annals of the University of Dunarea de Jos of Galati. Fascicle VI. Food Technology, 38(1), 9. 
Surowsky, B., Fischer, A., Schlueter, O., and Knorr, D. (2013). Cold plasma effects on enzyme activity in a model food system. Innovative Food Science and Emerging Technologies, 19, 146-152.

Takai, E., Kitano, K., Kuwabara, J., and Shiraki, K. (2012). Protein inactivation by low-temperature atmospheric pressure plasma in aqueous solution. Plasma Processes and Polymers, 9(1), 77-82.

Tappi, S., Berardinelli, A., Ragni, L., Dalla Rosa, M., Guarnieri, A., and Rocculi, P. (2014). Atmospheric gas plasma treatment of freshcut apples. Innovative Food Science and Emerging Technologies, 21, 114-122.

Tendero, C., Tixier, C., Tristant, P., Desmaison, J., and Leprince, P. (2006). Atmospheric pressure plasmas: A review. Spectrochimica Acta Part B: Atomic Spectroscopy, 61(1), 230.

Thirumdas, R., Kadam, D., and Annapure, U. S. (2017). Cold plasma: an alternative technology for starch modification. Food Biophysics, 12(1), 129-139.

Tseng, S., Abramzon, N., Jackson, J. O., and Lin, W. J. (2012). Gas discharge plasmas are effective in inactivating Bacillus and Clostridium spores. Applied Microbiology and Biotechnology, 93(6), 2563-2570.

Vleugels, M., Shama, G., Deng, X. T., Greenacre, E., Brocklehurst, T., and Kong, M. G. (2005). Atmospheric plasma inactivation of biofilmforming bacteria for food safety control.
IEEE Transactions on Plasma Science, 33(2), 824-828.

Wan, J., Coventry, J., Swiergon, P., Sanguansri, P., and Versteeg, C. (2009). Advances in innovative processing technologies for microbial inactivation and enhancement of food safety-pulsed electric field and lowtemperature plasma. Trends in Food Science and Technology, 20(9), 414-424.

Wu, T. Y., Sun, N. N., and Chau, C. F. (2018). Application of corona electrical discharge plasma on modifying the physicochemical properties of banana starch indigenous to Taiwan. Journal of Food and Drug Analysis, 26(1), 244-251.

Zhang, Y., He, S., and Simpson, B. K. (2018). Enzymes in food bioprocessing - novel food enzymes, applications, and related techniques. Current opinion in Food Science, 19, 30-35.

Zhao, Y. M., de Alba, M., Sun, D. W., andTiwari, B. (2019). Principles and recent applications of novel non-thermal processing technologies for the fish industry - a review. Critical Reviews in Food Science and Nutrition, 59(5), 728-742.

Zouelm, F., Abhari, K., Hosseini, H., and Khani, M. (2019). The Effects of Cold Plasma Application on Quality and Chemical Spoilage of Pacific White Shrimp (Litopenaeus vannamei) during Refrigerated Storage. Journal of Aquatic Food Product Technology, Pp. 1-13.

\section{How to cite this article:}

Pooja Saklani, Siddhnath, Sambit Kishor Das, Sarita Kumari Das, Subal Kumar Ghosh and Shiv Mohan Singh. 2019. Recent Development of Non-Thermal Cold Plasma Technology for Safe and Sustainable Seafood Processing: A Review. Int.J.Curr.Microbiol.App.Sci. 8(11): 2459-2476. doi: https://doi.org/10.20546/ijcmas.2019.811.284 